\title{
Hidden duodenal gastrointestinal stromal tumor
}

A 62-year-old woman was evaluated for iron deficiency anemia. She had no history of any medications, trauma, smoking, or alcohol consumption. On physical examination, the patient had a pale appearance, and tenderness in the epigastric region but no rigidity or rebound. Upper gastrointestinal endoscopy revealed the majority of the stomach and duodenal bulb to be normal. However, a well-hidden, red-colored, ulcerated lesion (diameter $2 \mathrm{~cm}$ ) was observed. The lesion was located mainly on the posterior side of the duodenal bulb, partly occupying the duodenal bulb, and extended to the descending duodenum ( $\bullet$ Fig. 1 and $\bullet$ Video 1). The appearance and size of the lesion suggested a gastrointestinal stromal tumor (GIST), and it was therefore removed surgically. Histopathological examination of the resected tissue confirmed GIST. The patient was discharged 3 days after the surgery, and was doing well at follow-up.

\section{Video 1}

A hidden, red-colored, ulcerated lesion (diameter $2 \mathrm{~cm}$ ) was observed. The lesion was located mainly on the posterior side of the duodenal bulb, partly occupying the duodenal bulb, and extended to the descending duodenum.
GISTs are the most common submucosal tumors of the gastrointestinal tract, representing $1 \%-3 \%$ of gastrointestinal malignancies. About $50 \%-60 \%$ of GISTs occur in the stomach, and about $20 \%-30 \%$ are malignant [1]. The duodenum is an uncommon location. Diagnosis of duodenal GIST is sometimes difficult, especially those arising in the posterior duodenal bulb. As peristalsis allows a better view of the duodenal bulb mucosa, observation of this area for a while during endoscopic examination is a feasible method of detecting hidden lesions.

Endoscopy_UCTN_Code_CCL_1AB_2AD_3AB

Competing interests: None

\section{Fatih Karaahmet ${ }^{1}$, Mevlut Hamamci ${ }^{1}$, Yusuf Coșkun ${ }^{1}$, Hakan Akıncı', Ilhami Yuksel ${ }^{1,2}$}

${ }^{1}$ Department of Gastroenterology, Dıskapı Yıldırım Beyazıt Educational and Research Hospital, Ankara, Turkey

${ }^{2}$ Department of Gastroenterology, Yıldırım Beyazıt University School of Medicine, Ankara, Turkey

\section{Reference}

1 Iorio $N$, Sawaya RA, Friedenberg FK. Review article: the biology, diagnosis and management of gastrointestinal stromal tumours. Aliment Pharmacol Ther 2014; 39: 1376 1386

\section{Bibliography}

Dol http://dx.doi.org/

10.1055/s-0034-1391499

Endoscopy 2015; 47: E176

(c) Georg Thieme Verlag KG

Stuttgart · New York

ISSN 0013-726X

\section{Corresponding author}

\section{Fatih Karaahmet, MD}

Department of Gastroenterology

Dışkapı Yıldıım Beyazıt Educational and Research

Hospital

06080 Altındag - Ankara

Turkey

Phone: +90-312-3186690

fatih_ares@yahoo.com.tr
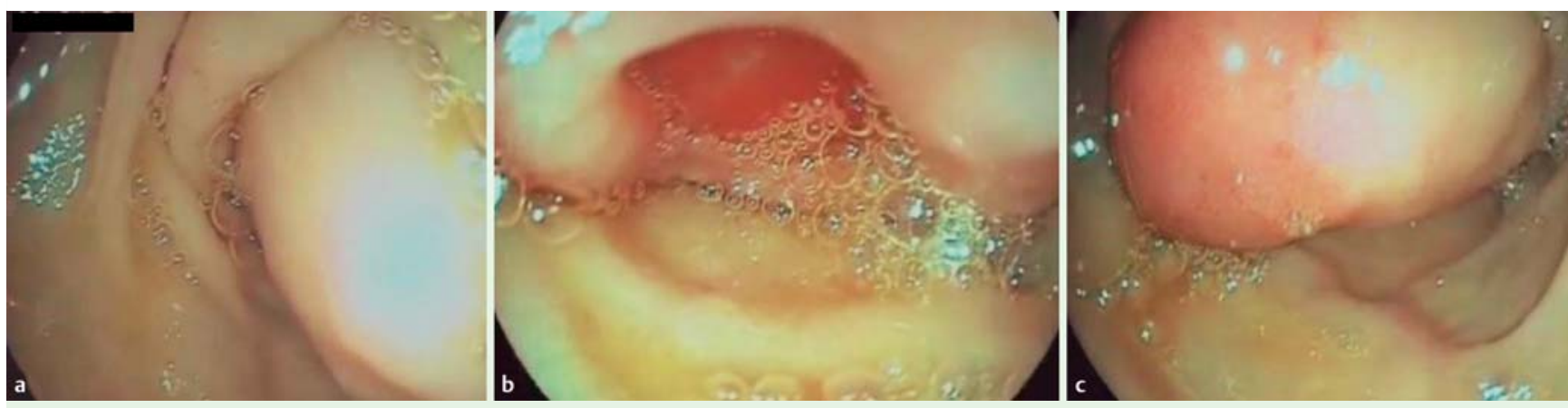

Fig. 1 Well-hidden gastrointestinal stromal tumor located on the posterior side of the duodenal bulb $(\mathbf{a}-\mathbf{c})$. 